\title{
SOME THOUGHTS ON THE CLINICAL EVALUATION OF DRUGS
}

\author{
James Parkhouse, M.A. (Oxon), M.D. (L'pool), F.F.A.R.C.S. \\ The Radcliffe Infirmary, Oxford
}

No REVOLUTION in medicine can compare with that brought about by the powerful therapeutic agents of today, and no change in thought compares with that brought about by increasing awareness, during the last 20 years, of the potentialities of the controlled clinical trial. We are beginning to emerge from the Dark Ages in our clinical assessment of drugs; further progress will depend on the clinician's ability to keep pace, in thought and deed, with the ingenuity of the scientist and the enthusiasm of the manufacturer.

In this world of drugs the doctor stands in the middle. On his one side is a vigorous and powerful industry; on his other a vast, curious, half-informed and gullible general public. The industry is not heedless of the well-being of patients and the opinion of medical authority, but it has other and more purely commercial concerns: as one firm candidly proclaimed, "What we do for the public good is a by-product of what we do for our own private good" (Lasagna, 1959). Neither is the public exclusively concerned with what the bestinformed medical opinion has to say: drugs are the brandy of our sophisticated age - an age not, perhaps, of damnation but of kicks, artifice and dependence, of adulteration, fortification and control, of stimulation, emulation and advertisement.

What are the medical implications of this complicated interplay between drugs and the life of the community, involving as it does not only the medicines with which we choose to dose ourselves but all that we eat, drink and inhale? Here is a large aspect of the large problem of private vice and the public weal - the doctor's dilemma in a new guise. Is it proper for the doctor to adopt an attitude to the community of "hear no evil, see no evil," confining himself strictly to the treatment of those specifically "medical" conditions about which people seek his advice? Is it right, by contrast, that he should become the arbiter of people's conduct, deciding, on grounds of health, what pleasures they may enjoy and how often? It is all too easy to envisage such a role when the Lancet's (1964) pleasing expression "Nothing to eat but food" so clearly promises to be supplanted by the more ominous reality "Nothing to eat but drugs." "Recent speculation," says a report submitted to President Johnson by his chief scientific advisors, "holds that the decline of the Roman Empire may have been due in part to lead poisoning of the Roman Governing Classes leading to infertility and general mental debility." The President's response has been to ask his Federal Health Department to set up a computer programme for the analysis of all known information concerning the toxic effects of chemicals on people (Guardian, 1966). It will be no surprise when this enquiry reveals what a thoroughly bad thing it is to be alive at the present time, and what hideous privations are required in order to stand an even chance of dying fit.**

The much more immediate problem, with which this paper is intended to deal, is the clinical testing of supposedly effective drugs. "Supposedly" is the operative work, for there are very many more-orless innocuous drugs sold over the counter and consumed by the ton without any clear picture of their therapeutic value having ever been drawn. Despite the fact, for example, that over 4,000 tons of aspirin are used every year in the United States alone (Grollman, 1965) we have astonishingly little information about its effect as an analgesic. It is only within the last three or four years that a really serious attempt has been made to study even small numbers of patients, after the administration of aspirin, in an attempt to obtain some quantitative assessment of pain relief. As with many proprietary drugs, the doctor is usually not interested enough to conduct a good clinical trial but he is only too ready to write prescriptions for his more bothersome patients.

Even when a drug seems harmless, albeit ineffective, some sad lessons have been learned through

**Medical Tribune (30 June, 1966) reports Dr. A. N. Howard as having recently said, "The person least likely to get atherosclerosis is a hypotensive, bicycling, unemployed, hypo-beta-lipoproteinic, hyper-alphalipoproteinic, non-smoking, hypolipaemic, underweight, premenopausal female dwarf living in a crowded room on the island of Crete before 1925 and subsisting on a diet of uncoated cereals, safflower-oil and water." 
the practice of direct sale, by advertisement, without the mediation of the medical profession. The mere changing of the vehicle in which a drug is dispensed can be a source of tragedy: the "elixir sulphanilamide" disaster in the United States did not occur so very long ago, but perhaps long enough to make it worthwhile drawing attention once more to the cogency of this horrid and lucidly told tale (Editorial, 1937). Evaluation presents a more obvious problem for the medical profession in the case of those drugs which have potentially dangerous side-effects in their own right - and such drugs are often of major therapeutic potential.

\section{The Place of the Controlled Trial}

A considered opinion, based upon valid and appropriately analysed evidence, will always be preferable to a collection of indiscriminate reports. Beecher (1952) has remarked that "After all the centuries morphine (or opium) has been used, "common sense" in this country (i.e. the U.S.) has arrived at a dose that is twice as large as the one that gives essentially the maximum pain relief." Our job is to prevent wastage and misinterpretation of clinical information.

The purpose of the controlled clinical trial, as commonly conceived, is to extract the maximum amount of useful information from the minimum number of patients. This is a sound principle, but with some inherent limitations. If only ten men are chosen from the population of Britain it may well happen that none is over $6^{\prime} 2^{\prime \prime}$ in height; however closely these men are investigated it is impossible to learn from them about people of $6^{\prime} 5^{\prime \prime}$. This fact often tends to be overlooked: that a highly detailed study of a small number of patients can never give information, except by accident, about the unusual responder, or the "freak" case which turns up only once in a while. This may be especially important when side-effects of drugs are in question, particularly those which are rare, and when there may be pharmacogenetic differences in the metabolism of a drug. It is also important when conclusions are extrapolated, for instance from one racial or social group to another.

The aim of using the smallest possible number of patients in a trial is reasonable so long as the trial has one specific purpose which is precisely known in advance. This concept is well exemplified by the sequential trial, which continues only until a predetermined end-point, in statistical terms, is reached. The study is quite valid as long as it is clearly understood that the investigator is concerning himself exclusively with a single question: whether or not a given degree of statistically "significant" difference can be demonstrated in respect of one specifically defined criterion. This single " $P$ " value is all-important, and no allowance is made for the study of "fringe benefits" in the form of incidental, perhaps unexpected and sometimes valuable information about other effects of the drug.

It is inevitable that a small trial must be highly specific in its design and terms of reference. It comes, increasingly, to resemble a laboratory experiment rather than a true model of the practical use of the drug. Here again the danger of extrapolation is apparent; conclusions derived from a crossover study of analgesics in hospital patients, each of whom has required three or four medications, cannot readily be applied to the man in the street who takes a single dose of aspirin for a headache; the results of a sedative study carried out on disturbed elderly patients in a mental hospital may not apply to a nurse who wants a sleeping tablet when she has just finished night duty. A good example of one aspect of the specificity problem is the study of postoperative vomiting: there are many factors at work, including the duration of operation, the premedication, the age and sex of the patient, the anaesthetic drugs used, the hospital environment and so forth. In an attempt to achieve control, elegant studies have been made (Riding, 1960) on a single type of case, dilatation and curettage; here all the patients are women, in a fairly closely defined age range, and the operation is a standardised procedure which can be performed under a single anaesthetic agent, intermittent thiopentone, so that one of the few remaining factors which can influence postoperative vomiting is the premedication. Much has been learned from these studies, but it must never be forgotten that the influence of premedication on vomiting in these highly specific circumstances may bear very little relationship to the plight of the patient who feels sick after a cholecystectomy or an ophthalmic operation.

Another aspect of the specificity problem in "highly controlled" trials is illustrated by studies which depend upon subjective evaluation, for instance most analgesic studies. Many investigators have now discovered that useful results can be obtained when a specially trained whole-time nurse or technician is employed to evaluate pain relief; as long as the same person makes the assessments throughout a study, meaningful results are obtained. But when a different observer takes over her scores may be quite different. It is slightly disturbing to find that two observers do not necessarily grade pain relief in the same way, and it invites some important questions: whose opinion is it that really matters, the patient's, the observer's or the doctor's and for that matter, which doctor's? A much more disturbing fact is that in some reports it seems to be only the "best" observers who obtain scores which show really clear differences between drugs at all; if future clinical trials are to pursue 
this trend we can look forward to the final absurdity of a situation in which all of us become dependent, to parody Sherrington, on one "ultimate pontifical girl" whose judgement ("double blind," of course) tell us whether one drug is better than another!

\section{What do we Really Want to Know?}

When we say that we want to know whether one drug is better than another, our terms of reference need defining with care. First of all there is the potency myth: the fact that one drug is more potent than another, in terms of the number of milligrams required to produce a therapeutic effect, if often of no consequence whatever. What matters is the relationship between the therapeutic dose and the dose which produces toxic effects. There are now synthetic morphine-like compounds so powerful that a milligram is an effective dose for an elephant weighing four tons; the difficulties of dispensing such a drug safely for human consumption are enormous, and there is no advantage to be gained when side-actions march hand in hand with potency. It is important, in designing a trial, to ensure that as far as possible drugs are studied in comparable doses; many a clinical trial has failed because the new drug was given in what subsequently proved to be an ineffective dose.

Despite an equal incidence, or lack, of side-effects there do seem to be some drugs which are more "effective" than others. But even here we must be sure that we know in what way we wish a new drug to be better than those previously available. The criteria for deciding that a drug is "better" or "preferable" have often been so loosely defined, or have represented a jumble of so many individual factors, that the trial has made little real contribution. This raises the question of the value of "composite indices." In rheumatoid arthritis, for instance, the effects of drugs may be assessed according to their influence on pain, morning stiffness, grip strength, sedimentation rate, and perhaps other features of the disease. A "composite index" of the efficacy of each drug can be created by adding up the "scores" for each of the measured aspects of improvement. From the statistical point of view there are some theoretical difficulties about this procedure, but it is important to realise that even from a purely practical point of view it presents problems. In each individual case of arthritis the aim of symptomatic treatment is to provide relief; and thus we need to know what it is that troubles each patient most: is it pain, or is it morning stiffness? It is unlikely to be sedimentation rate. The aim of curative treatment is to influence the primary pathological process, and we must know where to look for specific evidence of such influence. A "composite index" tells us merely that in a group of patients such and such a drug produces a better overall improvement than a standard preparation or a placebo. This is a blunderbuss method which exemplifies the statistical, and clinical, fallacy of supposing that the sensitivity of a trial can be increased by adding together individual measurements some of which are inherently more sensitive than others.

It should not need further emphasis that, as far as drugs are concerned, we live in a real world of people and not an imaginary world of statistics. What we really want to know is whether one drug is significantly better than another in terms of its clinical effect, and not whether it is "significantly" better than another in terms of some technique of statistical analysis. Statistics can help us a great deal, but they can never tell us in clinical terms whether a difference which has been shown to exist really matters. With recent advances in technology, for instance, it has become possible to make very precise and accurate measurements of $\mathrm{pH}, \mathrm{PcO}_{2}$, and indeed the blood concentration of many constituents. When groups of people are compared it is not therefore surprising that "statistically significant" differences can sometimes be demonstrated between representative sets of highly accurate readings which are closely gathered about their respective means. But whether these differences are "significant" in terms of health and disease remains an open question; we do not yet know the limits of normality with such precision as this.**

Most of our currently used statistical methods were developed in connection with agricultural experiments and other non-medical activities. The mathematician W. S. Gossett, when he described under the pseudonym "student" the t-test which has become a touchstone of medical statistics, was working for Guinness's brewery. Few attempts have been made to devise statistical procedures specifically applicable to medical problems, although specific enough problems certainly exist. Elegantly balanced studies in which "treatments" are allocated in orderly rotation to different "plots" are ideal when a whole experiment can be planned and predicted in advance. They do not always fit in with the ethics and exigencies of clinical medicine, in which it is comparatively rare to know in advance how a disease will develop, how many doses of a drug a patient will need, or what the consequences of new treatment may be. There is still too much dependence on the traditional methods, without enough thought for their appropriateness, while other, non-parametric, methods remain to some extent under a cloud for want of good evaluation.

\footnotetext{
**It might be added, as a further example of extrapolation from an unrepresentative group to the community as a whole, that a considerable number of our "normal" values are derived from a handful of medical students!
} 
Too much importance is attached to the mystique of " $\mathrm{P}=0.05$ " when it might be more appropriate to think in terms of how often is drug A likely to give a better result than drug $B$ in a particular situation, how is a certain type of patient likely to respond, what degree of difference is of "clinical significance," and how much the individual preferences of patients and the idiosyncratic reactions of a minority are likely to influence an evaluation; in general, there is a great deal to be learned about the statistics of subjective evaluation and of "clinical impressions." For all this we need many more people who are interested in bridging the gap between mathematical statistics and clinical medicine.

\section{Who Does the Trial?}

It is sometimes implied that the drug firms have no great difficulty in finding clinical investigators. In a sense this is true; there are always plenty of people who are willing to volunteer for the wrong reasons. A doctor may feel that it will help him in some way to carry out a clinical trial; there may be material benefit in his association with the company, it may enable him to attend a meeting or publish a paper, it may improve his standing in the eyes of his colleagues or simply make life more interesting for him. This kind of enthusiasm, whatever its underlying motive may be, sometimes results in a good clinical trial; but most manufacturers, when speaking frankly, are prepared to admit that they often have great difficulty in finding conscientious clinical investigators who are willing to do the study they want, in the way they would like it to be done. Many trials are much less valuable than they could have been, and many never even reach completion, because the initial enthusiasm has waned or because the essential "know how" was never there in the first place.

There are relatively few "big names" in medicine associated with the clinical evaluation of drugs; more often the authors whose names appear in connection with new compounds are otherwise unknown, and are not associated with the major university centres. This is not to imply that a hitherto unknown doctor is incapable of doing a good trial, or that the best work must necessarily come from the teaching centres, but it does imply much dependence on the firm for guidance, and it does suggest a certain caution on the part of some of the more eminent members of the profession about becomiris - volved in drug studies.** Some of this caution may be amply justified. It is in no

\footnotetext{
**When a man says he is too busy he usually means that he has other things to do which he considers more important. It would be regrettable if this were to be the attitude of those among us who are most capable of conducting good clinical trials.
}

small part a reaction to the enthusiastic promulgation of meretricious drugs. Naturally, if a firm is anxious to get a drug tried clinically it will not go out of its way to stress the fact that the drug probably has no great advantage. Likewise, the firm may be unwilling to divulge, unless pressed, that previous studies have proved disappointing or that other trials are actually in progress. Indeed, it may be quite difficult to find the names of other investigators. All this is unlikely to inspire confidence in the more discerning type of clinical investigator, but it should not lead him away from the essential issue: a good trial of a poor drug is a great deal better than no trial at all. It is infinitely better than a poor trial of a poor drug.

The case for good clinical pharmacology is nowadays generally admitted. Although one meets from time to time the comment that a controlled clinical trial is something which any doctor should be competent to undertake, there is in practice as much difference between idealism and realism in this respect as in the case of appendicectomy or caesarean section or any of the other procedures which any good doctor is, in theory, capable of performing. The truth about clinical investigations is that all doctors need good advice, some knowळ that they need it, and a few can recognise it when they get it. But despite a good deal of lip-service which has been paid to the need for adequate clinical trials, little has been done to facilitate their routine conduct. A much more positive approach is needed to clinical pharmacology (Hunter, 1966); it is pitiable that among the profusion of clinical reports which appear in the journals there are still a mere handful of "classical" studies (mostly quite long in the tooth) which are held up as examples of what can be done. Not only can such studies be done; they should by now be a standard procedure with potentially worthwhile new drugs.

The establishment of drug control, such as the present Dunlop Committee arrangements, does relatively little to encourage good clinical pharmacology. A mere expression of disapproval of what has already been done, or what it is proposed to do, is a poor substitute for constructive advice and practical help. Controls can actually become harmful if they create long delays and consequent frustration, ${ }^{* *}$ and if they jeopardise the chances of

\footnotetext{
**The next stage is to "pass the buck," as far as early clinical trials are concerned, to some other country with less stringent regulations. This is already happening, in a much-unpublicised way, with rather alarming consequences: a new hypnotic drug was recently launched in this country, complete with glossy trade literature and basic N.H.S. cost, at a time when no trial had been completed in Britain and the medical literature concerning the drug did not contain one word in the English language!
} 
drugs which, while admittedly toxic, may be of great value. It has been observed with some pertinence that if drug controls had been in operation in the past it is doubtful whether either morphine or digitalis would ever have been approved for clinical trial.** Whatever controls there may be, and the need for some is beyond doubt, they must certainly be administered with remarkable enlightenment if anomalies are to be avoided and if both drug firms and individual doctors are to feel satisfied that their freedom is not officiously being curbed. They are in any event no substitute for positive planning and definitive leadership in the conduct of the right kind of clinical trials.

\section{How Not to do It}

From the medical point of view it is clearly "wrong" of drug firms to "push" drugs which they know to be useless, however harmless they may appear to be. From the purely commercial point of view it is not for the medical practitioner to express an opinion on the rights and wrongs of advertising a worthless compound to the general public. It is, however, clearly "wrong" for drug firms to try and persuade doctors, either unwittingly or in exchange for some personal reward, to attach their names to trials which are fabricated in order to present compounds in an artificially favourable light, and no comment is necessary on the attitude of doctors who knowingly endorse such escapades. At the opposite extreme, it is "wrong" for medical practitioners to be interested only in drugs which promise to have outstanding advantages. Everybody wants to be the first to announce a penicillin or a cortisone to the world, but we should remember that even a small advantage in a new drug, if it is genuine, may be of great advantage when a large number of patients has to be treated. There is also plenty of valuable information to be obtained about some very homely drugs: one of the most striking things about analgesic studies, for example, is that almost every investigator has from time to time remarked that the most salutary experience for him has been not so much finding out about new drugs as discovering how much he did not previously know about morphine and aspirin.

The drug industry should not have to go cap-inhand to the medical profession to get worthwhile compounds tested. There should certainly be no

\footnotetext{
**"We find that the Golden Age of Medicine is being replaced by an Age of Destruction. Fear is replacing confidence in therapeutic agents ... None of us would minimise side-effects. The memory of Thalidomide is still green. But it is equally a disservice to the public to overstate the medical significance of side-effects when the preponderance of clinical evidence - often accumulated over years and years of clinical experience argues against such emphasis." (Hiebert, 1965).
}

question of having to "bribe" second-rate citizens in order to produce trials which may actually prejudice informed opinion against a drug, and its manufacturer, for many years to come. This is an entirely different thing from believing it to be right that a conscientious doctor who spends time and energy on a clinical study should go entirely unrewarded for his pains, especially since he may risk his reputation by giving a drug of unknown potential to his patients, and since his efforts may, albeit indirectly, earn many thousands of pounds for the manufacturer. Admittedly there is a need for caution in regard to personal rewards, but it is sheer nonsense to suggest that a clinical trial must be biassed because the investigator has been recompensed in some way.

It is possible to envisage an arrangement whereby the major drug firms would provide their own teams of clinical investigators, wholly employed by the industry and given access to hospital patients for the purpose of conducting clinical investigations. From the industry's point of view, this system would have the advantage of enabling each firm to make its own clinical assessment of its products in the same way that each makes its own pre-clinical assessment; $\stackrel{\odot}{\oplus}$ there is much to be said for the view that a reputable 2 firm should have the right to do this, without having to depend on what some "unbiased" doctor 8 chooses to disclose. The complete opposite of this is the purely academic trial which begins because at doctor is sufficiently impressed - or unimpressed by the claims for a drug that he decides on his own initiative that he wishes to study it, whether the manufacturer cares to co-operate with him or not. He may in fact choose to study the drug in open competition with a rival firm's product. It is wholly unreasonable to expect financial help from the drug industry for this type of investigation, although such help is often quite generously offered. The difficulty in practice is that unless a special arrangement has been made, as in the case of the M.R.C. Committee for the study of non-explosive anaesthetics, there are few doctors or even university departments who can afford to provide all the necessary facilities independently of the industry's help. The usual solution at present, therefore, lies in some form of compromise.

One form of compromise is for a firm to make a donation to departmental research funds in consideration of the trial which is being undertaken. this avoids personal payment to an individual doctor, but it has the great disadvantage of providing only for the particular trial of the moment. In the course of investigating a certain type of drug a university department may well be capable of creating a "set up" which would be extremely useful for the evaluation of many similar drugs, 
from different firms. But if the financial basis of this work is entirely hand-to-mouth, depending upon donations for individual trials, there is none of the security of tenure which would allow for the realistic employment of clinical investigators, biochemists, statisticians or other specialists who may be needed. Another embarrassment arises when comparable amounts of time and money have to be expended in the investigation of several drugs of which the manufacturers may have offered very different sums of money.** It has actually proved possible, at least in the United States, to maintain viable units by offering to conduct trials, rather than waiting to be approached, and stipulating to the manufacturer the cost at which each trial can be undertaken. There have been at least two privately managed clinical investigation units subsisting entirely on money provided by drug firms in this way. The unit has access to patients, and provides secretarial, laboratory and statistical facilities; the trial is planned jointly by the unit staff and the sponsoring manufacturer, agreed numbers of medications are supplied in coded form, the manufacturer retaining the key to the code. At the end of the trial results are analysed by the unit and reported to the firm in terms of the code, which is then "broken" to disclose the nature of the medication. In theory, the principle of impartiality is adhered to, although perhaps the opportunity for abuse, always present in a clinical trial, is more obvious with this system than with most others. It may not, furthermore, be regarded as wholly unexceptionable that such units work without the active support of academic institutions, and not necessarily on a non-profit making basis. On the whole, although the approach is both enterprising and instructive, it deserves its place under the present heading "How Not to do It."

Another commonly suggested compromise is for the manufacturing firm to handle all the biochemical and other investigations, and all the statistical analyses which are required, so that the doctors undertaking the trial are relieved of the need to find money and facilities for this work. It is, again, perfectly legitimate for the firm towish to make its own measurements and statistical analyses, but this is no substitute, in the eyes of the medical profession as a whole, for the "Caesar's wife" of an impartial biochemistry laboratory or a university statistical unit. Copies of data and aliquots of specimens can be sent to the manufacturer, so that he can perform whatever statistical and other manipulations he

\footnotetext{
**The system is, in practice, open to further abuse. A member of the staff of a university department (not in this country) once freely admitted to me that he was doing a number of rather tedious drug studies simply in order to obtain money for the non-pharmacological research which was his real interest.
}

may wish; but the clinical investigator should have not only the right, but the wherewithall to study his material independently.

\section{How to do It?}

Would it be feasible for the major drug firms to combine, in their own interests, and offer a grant towards the establishment of a number of departments or units of clinical investigation in university centres? At the same time, could not some of our universities step forward to indicate their willingness to house such units, and contribute to the cost of their maintenance. It may be felt appropriate to create a Chair or Readership in clinical pharmacology, or alternatively to place money and facilities at the disposal of established groups of clinicians. The units so created would be available for the actual conduct of clinical trials, and also to offer advice to any practitioner who wished, on his own initiative, to investigate a drug or who was approached independently by a firm. The units would be assured of having money available to maintain staff and equipment, regardless of the number of trials being undertaken at any given time, and they would exist on the understanding that any firm's products could and would be investigated at the discretion of the clinicians concerned. It would thus be open to the drug industry to bring promising new compounds to the attention of the several units, and it would then be for each individual unit to decide whether it wished to undertake a trial. One would anticipate free discussion between the manufacturing firms, the clinical pharmacology units, and the Dunlop Committee. No compulsion would exist for doctors to avail themselves of the help of a clinical pharmacology unit; individual freedom would be in no way diminished in this respect. But the presence in the country of a number of focal points of informed opinion would stimulate critical thought about all published trials and would inevitably lead to a general rise in standards. At the same time, the existence of groups of academically recognised clinical pharmacologists in the universities would act as a foil to the activities of a centrally controlled Dunlop Committee and would, hopefully, lead to an abandonment of $e x$ cathedra pronouncements in favour of mutually advantageous discussions.

It is hard to believe that the full potential of contemporary pharmacological progress can be exploited without better-planned co-operation between the drug industry, the medical profession, the universities and the government. Control is needed, but so is initiative. Where is the first Captain of Industry who will step forward to do, for his own ultimate good, what Lord Nuffield had the foresight to do for others', and where is the Oxford that will lead his gesture to fulfillment? 


\section{REFERENCES}

Beecher, H. K. (1953): Experimental Pharmacology and Measurement of the Subjective Response. Science, 116, 157.

EDITORIAL (1937): Deaths due to Elixir of SulfanilamideMassengill. J. Amer. med. Ass., 109, 1985.

Grollman, A. (1965): The Efficiency and Therapeutic Utility of Home Remedies. Ann. N.Y. Acad. Sci., 120, 911.

GUARDIAN (1966): 21 June.
Hiebert, J. M. (1965): The Public Responsibilities of the Manufacturers of Home Remedies. Ann. N.Y. Acad. Sci., 120, 872.

HUNTER, A. R. (1966): Clinical Pharmacology. Lancet, i, 664.

LASAGNA, L. (1959): Gripesmanship: a Positive Approach. J. chron. Dis., 10, 459.

LeAding ARTICle (1964): Nothing to Eat But Food. Lancet, i, 593.

Riding, J. E. (1960): Postoperative Vomiting. Proc. roy. Soc. Med., 53, 671 . 